\title{
RECOMENDAÇÕES PARA DESENVOLVIMENTO DE INTERFACE PARA ESTIMULAÇÃO DAS INTELIGÊNCIAS MÚLTIPLAS EM CRIANÇAS DE 3 A 5 ANOS
}

\author{
Luana Bittencourt Saraiva \\ Faculdade Fucapi - Instituto de Ensino Superior Fucapi \\ bitluana@gmail.com
}

Alexandre Santos de Oliveira

Instituto Federal de Educação Ciência e Tecnologia de Rondônia - IFRO

olialx@gmail.com

\begin{abstract}
Resumo: Com a popularização dos smartphones, há grande quantidade de aplicativos que não oferecem conteúdos que estimulem as potencialidades infantis. Considerando este cenário, esta comunicação apresenta os resultados do projeto que teve como objetivo o desenvolvimento de recomendações para desenvolvimento de interfaces mobile que estimulem as inteligências múltiplas em crianças de 3 a 5 anos, através do conhecimento das suas características e estudo da contribuição dos jogos na educação infantil. O método empregado consistiu em pesquisa qualitativa, exploratória e descritiva, utilizando uma abordagem híbrida, empregando métodos propostos por Bomfim (1995) e Inhamuns (2011). As principais bases teóricas foram Piaget por meio de Barros (2000); Gardner (1995); e Antunes (1998). Como resultado, são apresentadas recomendações para o desenvolvimento de interface mobile que estimulem as inteligências múltiplas.
\end{abstract}

Palavras-chave: Interface mobile, crianças, inteligências múltiplas

\begin{abstract}
With the popularity of smartphones, there are lots of applications that do not offer content that stimulate children's potential. Considering this scenario, this communication objective to present the project results which aimed to develop recommendations for the development of mobile interfaces that encourage multiple intelligences in 3 to 5 years children through the knowledge of their characteristics and study of games contribution in early childhood education. The method employed consisted of qualitative, exploratory and descriptive research, using a hybrid approach, using methods proposed by Bomfim (1995) and Inhamuns (2011). The main theoretical bases were Piaget by Barros (2000); Gardner (1995); and Antunes (1998). As a result, recommendations are drawn up for the development of interface that stimulate multiple intelligences.
\end{abstract}

Keywords: Interface Mobile, children, multiple intelligences 


\section{INTRODUÇÃO}

No contexto das crianças em idade pré-escolar e seu contato com a tecnologia (computadores, smartphones e tablets), observa-se uma grande oferta de aplicativos em lojas virtuais, sem correspondência com sua qualidade, uma vez que muitas das aplicações oferecidas possuem o objetivo apenas de entreter e distrair. Assim, faz-se necessário utilizar o momento desse contato para oferecer um conteúdo lúdico e educacional, de forma a estimular as potencialidades próprias da idade em que as crianças fazem descobertas diárias.

As múltiplas inteligências consistem em um número desconhecido de capacidades humanas diferenciadas, variando desde a inteligência musical até a inteligência envolvida no entendimento de si mesmo (GARDNER, 1995). Para Antunes (1998), o jogo, em sentido integral, é o mais eficiente meio estimulador dessas inteligências. Por meio dele, pode-se reunir uma série de atividades que venham a ser utilizadas como complemento às atividades executadas em sala de aula. Sendo assim, o projeto em questão teve como objetivo o desenvolvimento de recomendações para o desenvolvimento de interfaces mobile que auxiliem a estimulação das inteligências múltiplas em crianças de 3 a 5 anos. Seguindo uma abordagem qualitativa, o método empregado caracterizou-se como pesquisa aplicada, exploratória e descritiva. Para atingir ao objetivo citado, utilizou-se uma abordagem metodológica híbrida, mesclando-se o método cíclico proposto por Bomfim (1995), em que os outputs de uma etapa fornecem as informações necessárias para os inputs da etapa seguinte, possibilitando o retorno entre elas, além do método utilizado por Inhamuns (2011), que, após a identificação do problema, referencial teórico e análise de similares, elabora recomendações para o desenvolvimento de interfaces específicas.

Para fornecer as bases teóricas e fundamentar a lista de recomendações, fez-se necessário o conhecimento das características do desenvolvimento cognitivo das crianças de 3 a 5 anos e a contribuição dos jogos na educação infantil e no desenvolvimento das múltiplas inteligências. Assim sendo, estudou-se a obra de Piaget, por meio de Barros (2000), quanto aos aspectos cognitivos; a obra de Gardner (1995) e sua abordagem sobre as inteligências múltiplas; e a obra de Antunes (1998), quanto à utilização de jogos para a estimulação das inteligências múltiplas na idade pré-escolar.

Além dessas principais bases teóricas, foi estudado o Design de Informação e usabilidade para o público infantil, a fim de buscar parâmetros para interfaces fáceis de entender e simples de usar (MUNARI, 2008); (NIELSEN, 2010); (MANO, 2005). Para ser atrativa e condizente aos usuários, estudou-se a linguagem visual (GOMES FILHO, 2000); (DONDIS, 1997); e, por fim, realizou-se análise de interfaces similares com base no referencial teórico, evidenciando os pontos positivos, que podem ser recomendados no trabalho em questão, bem como seus pontos negativos, que devem ser evitados e/ou melhorados.

Como resultado, é apresentada a lista de recomendações para o desenvolvimento de interfaces voltadas para a estimulação das inteligências múltiplas. Tais recomendações são categorizadas segundos os critérios abordados ao longo do projeto, enriquecidos com as orientações propostas pela Apple, em sua "iOS Human Interface Guidelines" (Apple Inc, 2014a), que orienta designers e programadores sobre as melhores práticas de interação. 
Este trabalho está dividido em quatro blocos. No primeiro apresentamos os conceitos chave da pesquisa, ou seja, as inteligências múltiplas, os conceitos de desenvolvimento de interfaces e o universo do público infantil. No segundo bloco é apresentada a análise de três interfaces similares para avaliação de tendências e pontos positivos. Por fim, no terceiro bloco compilamos as informações obtidas nos tópicos anteriores na forma de recomendações para o desenvolvimento de interfaces para a estimulação das inteligências múltiplas, perfazendo o resultado do projeto.

\section{INTELIGÊNCIAS, INTERFACES E O UNIVERSO INFANTIL}

Esta seção tem como objetivo apresentar os fundamentos teóricos que norteiam a compreensão sobre os aspectos que envolvem as características do público alvo, (crianças de 3 a 5 anos) determinantes para a projetação de interfaces.

\subsection{Aspectos cognitivos do estágio pré-operatório}

É necessário tomar como ponto de partida o conhecimento do público-alvo e seu desenvolvimento cognitivo, neste caso, crianças de 3 a 5 anos de idade. Barros (2000) explica que o desenvolvimento cognitivo é o processo gradativo da habilidade dos seres humanos no sentido de obterem conhecimento e se aperfeiçoarem intelectualmente. A compreensão do processo cognitivo evita dois inconvenientes: ensinar a criança antes que ela esteja pronta para aprender e perder uma oportunidade preciosa por ensiná-la muito tempo após o momento adequado.

Gardner (1995) confirma este conceito ao argumentar que as inteligências se manifestam de maneiras diferentes em níveis desenvolvimentais diferentes, e, por isso, tanto a avaliação quanto a estimulação precisam ocorrer de maneira adequada.

Segundo Piaget, citado por Bock, Furtado e Teixeira (1991), cada período é caracterizado por aquilo que de melhor o indivíduo consegue fazer nessas faixas etárias. Piaget divide o desenvolvimento humano em quatro períodos: sensório-motor (0 a 2 anos); pré-operatório (2 a 7 anos); operações concretas (7 a 11 ou 12 anos); e operações formais (11 ou 12 anos em diante). Todos os indivíduos passam por todas essas fases ou períodos, nessa sequência, porém, o início e o término de cada uma delas depende das características biológicas do indivíduo e de fatores educacionais e sociais.

Por outro lado, Barros (2000) afirma que o principal progresso desse período em relação ao sensório-motor, é o desenvolvimento da capacidade simbólica. A criança começa a usar símbolos mentais - imagens ou palavras - que representam objetos que não estão presentes. Assim amplia-se, neste estágio, o domínio do mundo, multiplicando-se o interesse pelas diferentes atividades e objetos, diferenciam e regularizam, isto é, tornam-se estáveis, sendo que a partir desses interesses, surge uma escala de valores própria da criança, onde ela passa a avaliar suas próprias ações a partir desta escala.

Barros (2000) elucida de forma sucinta as principais características que Piaget concluiu sobre o pensamento infantil nesta fase: Egocentrismo - As crianças pequenas (4 ou 5 anos) são incapazes de aceitar o ponto de vista de outra pessoa, quando diferente do delas; Centralização - Geralmente, a criança consegue perceber apenas um dos aspectos de um objeto ou acontecimento, não relacionando entre si os diferentes aspectos ou dimensões de uma situação; Animismo - A criança atribui vida aos objetos, isto é, supõem que os objetos são vivos e capazes de sentir; Realismo 
nominal - Pensa que o nome faz parte do objeto, que é uma propriedade do objeto que ele representa; Classificação - Agrupam objetos sem critérios, pois não têm uma concepção real de princípios abstratos que orientam a classificação; Inclusão de classe - Piaget nota que a criança tem dificuldade em entender que uma coisa possa pertencer, ao mesmo tempo, a duas classes; Seriação - Crianças pequenas não são capazes de lidar com problemas de ordenação ou de seriação, conforme Piaget.

Outras características importantes listadas por Piaget (MANO; CAMPOS, 2006) são: Raciocínio transdutivo - As crianças tentam sempre encontrar uma causa para tudo, e frequentemente estabelecem relações de causa-efeito, ligando fatos que não estão relacionados; Reversibilidade - As crianças normalmente apenas consideram o momento presente. Não são capazes de desfazer mentalmente uma ação e tornar a fazê-la; Intuição - As crianças julgam muitas vezes as situações pelos dados que podem captar pelos seus sentidos. Se estes dados não são ajustados pelo seu raciocínio, podem não ser capazes de avaliar as situações corretamente; Sincretismo - É um modelo de raciocínio que toma a parte pelo todo. Manifesta-se quando as crianças não são capazes de separar diferentes aspectos ou partes de uma situação ou objeto e agir de acordo com as suas características.

Portanto, é nesta fase de desenvolvimento que as crianças passam a querer entender o mundo a partir de suas próprias teorias e conceitos. De acordo com Gardner (1995), elas também desenvolvem pelo menos um nível inicial de competência em relação aos sistemas simbólicos humanos básicos - linguagem, número, música, descrição bidimensional, e assim por diante. As crianças desenvolvem essas habilidades simbólicas e estes conceitos teóricos principalmente por meio de suas interações espontâneas com o mundo no qual vivem, sem a necessidade de instrução explícita.

\subsection{Linguagem Visual para o público infantil}

O universo infantil é repleto de cores, formas, texturas, tamanhos e fantasia. A partir disso, observa-se que o visual não é um elemento supérfluo, mas informacional, uma vez que, de acordo com Teixeira (2008), interfere na construção do conhecimento, pois apresenta à criança significados, modelos e outros referenciais imagéticos que contribuirão para a sua compreensão de mundo. As crianças da faixa etária compreendida entre os três e cinco anos de idade ainda não chegaram à fase de alfabetização e, dessa forma, faz-se necessário o estudo da linguagem visual, principal meio de comunicação do público.

Quanto às formas, Gomes Filho (2000) afirma que a tendência à simplicidade é uma constante em nossa mente, pois buscamos sempre uma estrutura mais simples, com o mínimo de elementos, proporcionando uma leitura clara e consequentemente em menor tempo.

Quanto às cores, Dondis (1997) se baseia na saturação, segunda dimensão da cor, para apontar a preferência das crianças. Segundo o autor, uma cor saturada é uma cor simples, quase primitiva, é explícita e inequívoca; Quanto mais intensa ou saturada for à coloração de um objeto ou acontecimento visual, mais carregado estará de expressão e emoção. Sendo assim, são preferidas pelas crianças.

Evidenciando que a linguagem visual de um produto não é apenas uma questão estética, Preece, Roger e Sharp (2005) abordam que o estilo de uma interface, no que diz respeito a formas, fontes, cores e elementos gráficos que são utilizados e a maneira 
como são combinados, têm influência em se determinar quão agradável é interagir com eles. Isso quer dizer que, quanto mais eficaz for o uso das imagens em uma interface, mais envolvente e agradável ela será (MULLET; SANO, 1995 apud PREECE; ROGER; SHARP, 2005).

\subsection{As inteligências múltiplas e sua estimulação na educação infantil}

Gardner (1995) utiliza o termo "múltiplo" para enfatizar um número desconhecido de capacidades humanas diferenciadas, variando desde a inteligência musical até a inteligência envolvida no entendimento de si mesmo; e o termo "inteligências" para salientar que estas capacidades eram tão fundamentais quanto àquelas historicamente capturadas pelos testes de Q.I.. O autor classifica sete inteligências: Lógico-matemática: Esta inteligência se manifesta através da facilidade para o cálculo, na capacidade de se perceber a geometria nos espaços e na satisfação em criar e solucionar problemas lógicos. (ANTUNES, 1998). Espacial: Capacidade em se perceber formas iguais ou diferentes em objetos apresentados sob outros ângulos, em identificar o mundo visual com precisão e em ser capaz de recriar aspectos da experiência visual, mesmo distante de estímulos relevantes. (ANTUNES, 1998). Musical: Os estudos sobre o desenvolvimento dos bebês sugerem que existe uma capacidade computacional "pura" no início da infância. Finalmente, a notação musical oferece um sistema simbólico acessível e lúdico. (GARDNER, 1995, P. 22). Cinestésicocorporal e a motricidade: Manifesta-se pela capacidade de resolver problemas ou elaborar produtos, utilizando o corpo e seus movimentos de maneira altamente diferenciada e hábil, para propósitos expressivos. (ANTUNES, 1998). Linguística: O dom da linguagem é universal, e seu desenvolvimento nas crianças é surpreendentemente constante em todas as culturas. (GARDNER, 1995, P. 25). Interpessoal: Segundo Gardner (1995), esta inteligência está baseada numa capacidade nuclear de perceber distinções entre os outros; em especial, contrastes em seus estados de ânimo, temperamentos, motivações e intenções. Intrapessoal: De acordo com Gardner (1995), esta inteligência diz respeito ao conhecimento dos aspectos internos de uma pessoa: à capacidade de discriminar emoções e eventualmente rotulá-las e utilizá-las como uma maneira de entender e orientar o próprio comportamento.

Antunes (1998) adiciona a esta lista as inteligências naturalista e pictórica e explica cada uma delas: Naturalista: Competência para perceber a natureza de maneira integral e sentir processos de acentuada empatia com animais e com as plantas. Pictórica: Manifesta-se pela competência em se expressar ou em se compreender a linguagem dos signos, das cores ou de desenhos, permitindo melhor desempenho em tarefas mais complexas, como a escrita e a leitura.

Para Antunes (1998), o jogo, em sentido integral, é o mais eficiente meio estimulador dessas inteligências. Socialmente, o jogo impõe o controle dos impulsos, a aceitação das regras, mas sem que se aliene a elas, posto que são as mesmas estabelecidas pelos que jogam e não impostas por qualquer estrutura alienante. Brincando com sua espacialidade, a criança se envolve na fantasia e constrói um atalho entre o mundo inconsciente, onde desejaria viver, e o mundo real, onde precisa conviver.

Antunes (1998) afirma que existem quatro elementos que justificam e, de certa forma, condicionam a aplicação dos jogos na educação. São os seguintes: Capacidade de se constituir em um fator de autoestima do aluno: É importante que o educador 
possa organizá-los para simbolizarem desafios intrigantes e estimulantes, mas possíveis de serem concretizados pelos alunos, individualmente ou em grupo, dando algumas "dicas" facilitadoras quando o jogo é muito difícil, ou criar estratégias mais complexas, se julga de fácil solução. Condições psicológicas favoráveis: 0 jogo jamais pode surgir como "trabalho" ou estar associado a alguma forma de sanção, mas sim utilizado como ferramenta de combate à apatia e como instrumento de inserção e desafios grupais. Fundamentos técnicos: Um jogo jamais deve ser interrompido e, sempre que possível, o aluno deve ser estimulado a buscar seus próprios caminhos. Além disso, todo jogo precisa sempre ter começo, meio e fim e não ser programado se existir dúvidas sobre as possibilidades de sua integral consecução.

\subsection{Design de Informação}

O Design de Informação é a área do conhecimento que contribui para o desenvolvimento de informação significativa e experiências agradáveis. Horn (1999 apud Portugal, 2010), o define como a ciência de preparar as informações para que elas possam ser usadas por pessoas com eficiência e eficácia. Seus objetivos principais são: (1) Desenvolver documentos que sejam compreensíveis, precisos e rapidamente recuperáveis, e fáceis de transformar-se em ações efetivas. (2) Projetar interações através de equipamentos que sejam naturais, fáceis e agradáveis.

Segundo Lapolli, Vanzin e Ulbricht (2014), para tornar uma grande quantidade de informações facilmente acessível aos usuários, a informação necessita estar préestruturada, devendo comunicar algo ao público. Essa organização possibilita que as informações sejam recuperadas, encontradas e visualizadas mais facilmente. Para serem visualizadas facilmente, faz-se necessária a utilização dos atributos visuais da forma, como cores e contrastes, tamanhos, textura. lida (2005) complementa esta afirmação, ao recomendar que as representações gráficas devam mostrar a evolução do sistema de forma mais direta possível, diminuindo as operações mentais para interpretar as informações, reduzindo-se o tempo de reação, para que o usuário tenha eficácia na realização de suas tarefas.

Além disso, Lapolli, Vanzin e Ulbricht (2014) abordam o uso de metáforas visuais como uma forma para transmitir mensagens de forma rápida e clara, pois são constituídas por imagens e conceitos que remetem a elementos do mundo real, baseados nas experiências anteriores dos intérpretes. Aplicando-se ao contexto do mundo infantil, podem ser utilizados elementos dos ambientes e objetos com os quais estão familiarizados, como parques, creches, brinquedos e jogos.

Em relação aos aplicativos para dispositivos móveis, sobretudo os jogos digitais, os elementos gráficos admitem três funções básicas que apoiam as demandas informacionais dos usuários para execução de suas tarefas e ações. Farias e Teixeira (2013) citam os estudos de Xavier (2010) e Cybis (2010), e enumeram essas funções: Navegação - é o deslocamento no ambiente virtual que antecede a principal atividade do jogo. Esse deslocamento é motivado por interesses como definir uma tática, equipar o avatar, selecionar um equipamento, escolher uma fase, etc. Instrução - é a atividade de treinar o jogador sobre os elementos do sistema, no qual permite que ele aprenda a controlar os componentes presentes. Desta forma, as instruções demandam competências linguísticas, cognitivas e motoras. Comunicação interativa - são os dispositivos de entrada e saída, os quais podem ocorrer mediante elementos gráficos e/ou gestuais. 
Sendo assim, de acordo com Portugal (2010), os princípios que norteiam o campo do Design da Informação são poderosos instrumentos para potencializar o raciocínio sobre as interfaces. Com as novas evoluções tecnológicas, a instrução não deve limitar-se a comunicação verbal e, sobretudo nos produtos direcionados às crianças, devem-se associar gráficos, tipografia, movimento, som e interatividade de forma compreensível e enriquecedora. Segundo a autora supracitada, a organização e apresentação de dados e a sua transformação em informações devem ser válidas e significativas e possibilitar a ação efetiva na comunicação.

\subsection{Usabilidade em interfaces para crianças}

Para se concluir o referencial teórico de estudo do público-alvo, é imprescindível conhecer as normas que norteiam os designers para alcançar a usabilidade em interfaces para crianças, pois, de acordo com Munari (2008), o jogo ou brinquedo deve ser fácil de entender e simples de usar, ou seja, que a criança entenda sem necessidade de explicações sobre o que é e como se usa, além de comunicar efetivamente o que se pretende.

A norma ISO 9241-11/NBR 9241 citada por Kulpa (2009) conceitua usabilidade como a medida na qual um produto pode ser utilizado por usuários específicos para alcançar objetivos específicos com eficácia, eficiência e satisfação em um contexto específico de uso. Segundo lida (2005), esses objetivos podem ser atingidos se os produtos forem fáceis de usar, fáceis de entender, fáceis de operar e pouco sensíveis a erros. De forma simples, Krug (2010) resume a usabilidade em assegurar-se de que algo funcione bem: que uma pessoa com habilidade e experiência comuns (ou até menos) possa usar algo - seja um web site, um caça a jato ou uma porta giratória para seu propósito desejado sem ficar frustrado com isso.

Com a evolução da tecnologia e aprimoramento de gráficos, animações, cores, vídeos, sons e imagens, os recursos acessados pelo computador tornaram-se mais interessantes e atrativos. Da mesma forma, os problemas de usabilidade evoluíram, apresentando impactos negativos para os usuários.

Apesar do crescimento em usuários e serviços, pouco se sabe sobre como as crianças realmente usam sites ${ }^{1}$ ou como projetar sites que serão fáceis para eles usarem (NIELSEN, 2010). Um grande avanço nesta área foi o estudo realizado em 2002 por Nielsen Norman Group, sendo referência para pesquisadores de usabilidade voltados ao público infantil. O estudo foi feito nos Estados Unidos e Israel, com 55 crianças de 3 a 12 anos, que navegaram em 24 web sites criados para crianças, e três orientados para utilizadores adultos.

De uma forma resumida, as conclusões retiradas do estudo são: (a) As crianças exercem uma navegação mais exploratória na web, a qual é fomentada pelos feedbacks de animações e sons dos elementos que compõem as interfaces. No entanto, muitas destas características podem acabar confundindo os adultos, assim como as próprias crianças. (b) As crianças têm uma predisposição a repetir caminhos aprendidos: elas tendem a reutilizar o mesmo método que empregaram anteriormente ao iniciar uma ação, mesmo que ela falhasse em tarefas subsequentes, as quais as exigiriam outro método para navegação. (NIELSEN, 2010). (c) O objetivo das

\footnotetext{
${ }^{1}$ Abranger o termo sites aos demais ambientes virtuais utilizados pelas crianças, como jogos virtuais, aplicativos, videogames, etc.
} 
crianças em utilizar mídias digitais é a diversão, ou seja, não se deve esquecer o seu caráter lúdico. (d) Não possuem grande disposição em esperar; desejam gratificação instantânea; (e) Preferem controlar inteiramente a navegação e o seu ambiente de trabalho na web. (f) Não utilizam o botão Voltar. (g) As metáforas da vida real são muito úteis para crianças que ainda não leem. (h) Utilizar fontes grandes (14 pontos). (i) As crianças raramente utilizam a rolagem da tela. (j) Utilizar sons e motivação para atrair a atenção das crianças. (k) As diferenças de gênero e idade são mais pronunciadas nas crianças.

Além do estudo de Nilsen (2010), Mano (2005) cita a pesquisa de Nicol e Casey em que testaram alguns guidelines com crianças em idade pré-escolar, num estudo orientado para a aquisição de competências na escrita e leitura. Educadores e especialistas na criação de software para crianças foram entrevistados para estabelecer um conjunto de guidelines que pudessem ser testados. As guidelines estabelecidas que são importantes para o trabalho em questão são: (a) evitar o uso do texto como mecanismo de resposta da interface; (b) utilizar ajuda inteligente e automática; (c) evitar a introdução de dados através do teclado; (d) permitir a configuração da aplicação, mas torná-la inacessível às crianças; (e) utilizar aleatoriedade, ou seja, obrigar as crianças a pensar sobre as tarefas, variando o aspecto da interface.

Em vista a todas as normas apresentadas e guidelines baseadas em anos de pesquisas, busca-se realizar lista de recomendações para interface com foco no usuário e nas suas características marcantes quando utilizam aplicações digitais, sem com isso "engessar" a interface do jogo, pois este deve ser prioritariamente divertido, lúdico, possuir aspectos engraçados, surpreendentes, estimulando a comunicação, a interação com as demais crianças, além de instigar a criatividade e fantasia.

\section{ANÁLISE DE INTERFACES SIMILARES}

Nesta fase foi realizada análise de três aplicativos educacionais, levantando seus pontos positivos e negativos. Somados aos conhecimentos adquiridos no item anterior, será possível estabelecer recomendações para desenvolvimento de interface. Os aplicativos analisados foram:

\section{Playkids:}

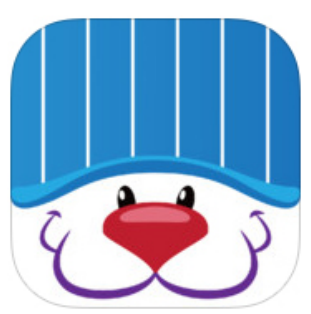

Figura 1 - Ícone do aplicativo PlayKids para IPhone Fonte: Apple Inc (2014b)

Desenvolvido pela Movile Internet Movel S.A., este aplicativo infantil (Figura 1) é direcionado para crianças com até 5 anos e foi eleito como finalista dos melhores de 2013 da Apple. Entre os jogos oferecidos estão jogo da memória, quebra-cabeças e livro de colorir (Figura 2). 


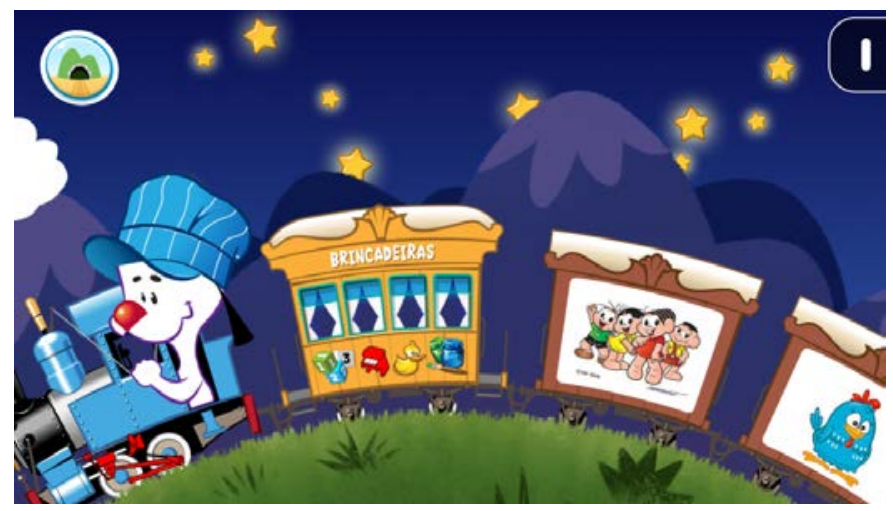

Figura 2 - Tela inicial do aplicativo PlayKids

Fonte: Movile Internet Movel S.A (2014)

\section{Talking Pokoyo:}

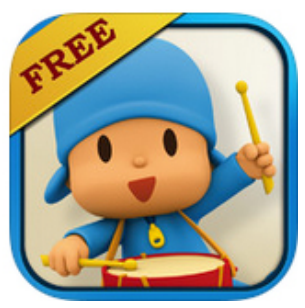

Figura 3 - Ícone do aplicativo Talking Pocoyo Free para IPhone Fonte: Apple Inc (2014c)

O menino Pocoyo representa uma criança de 2 anos, aproximadamente, que interage de muitas formas, com risadas e imitações. Desenvolvido pela Zinkia Entertainment, S.A., este aplicativo infantil (Figura 3) oferece não apenas o recurso da fala repetida (Figura 4), mas também reage quando é tocado, imita animais, toca vários instrumentos musicais e dança de forma animada, estimulando a interação da criança com o personagem.

(1)

19

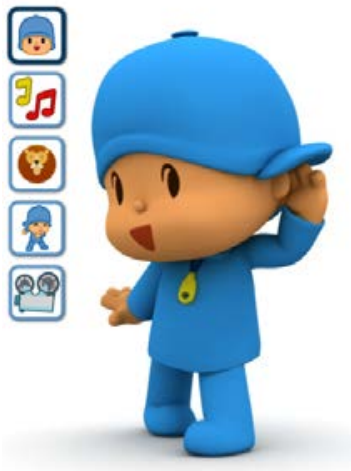

Figura 4 - Pocoyo mostrando que está ouvindo o que a criança está falando Fonte: Zinkia Entertainment, S.A. (2014) 


\section{Agnitus Kids Learnig Program:}

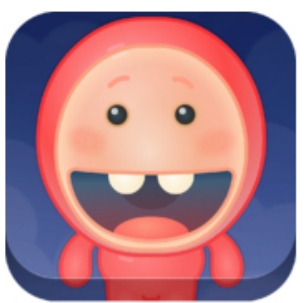

Figura 5 - Ícone do aplicativo Agnitus para IPhone Fonte: Apple Inc (2014d)

Desenvolvido pela Agnitus (Figura 5), este é um dos aplicativos educacionais infantis mais completos direcionados para crianças de 2 a 5 anos. As mais de 45 atividades oferecidas são baseadas nas habilidades das crianças da pré-escola e jardim de infância (Figura 6), além de fornecer aos pais um relatório detalhado do desempenho dos filhos. Possui vários prêmios em sua categoria, como o Family \& Parent Choice Award 2014.

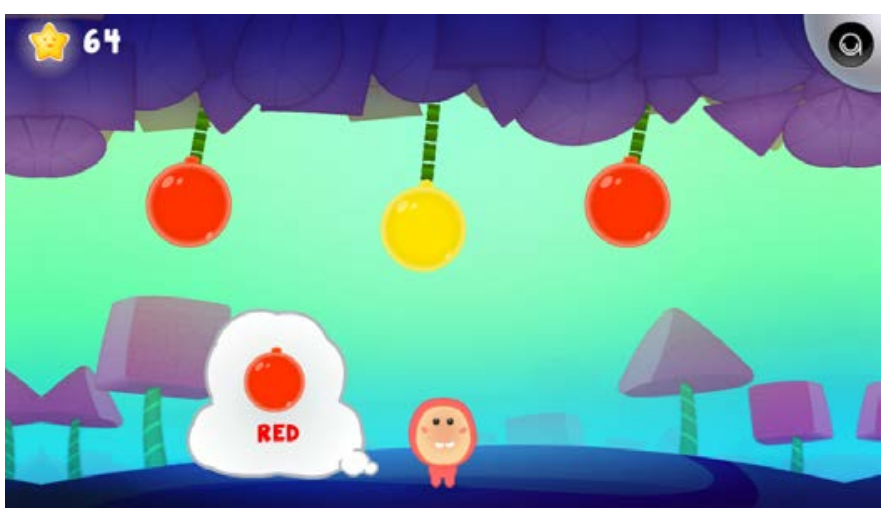

Figura 6 - Tela de exemplo da interface e seus elementos Fonte: Agnitus Inc (2014)

Como pontos negativos, verificou-se que as aplicações não possuem um "fim" para os jogos, ou premiações que estimulem o caráter desafiador nas crianças, contrapondo Antunes (1998), que afirma que todo jogo precisa sempre ter começo, meio e fim. Outro ponto negativo analisado é que, quando a criança erra repetidas vezes, os aplicativos não fornecem "dicas", mas cancela o jogo, passando para um próximo. Antunes (1998) recomenda que os desafios devam ser intrigantes e estimulantes, mas possíveis de serem concretizados pelos alunos, dando algumas "dicas" facilitadoras quando o jogo é muito difícil. Finalmente, as aplicações "Playkids" e "Talking Pokoyo" apresentam inconsistência em determinadas telas, opondo-se ao princípio de usabilidade "consistência e padrões".

Quanto aos pontos positivos, observou-se que as aplicações são intuitivas, combinando texto e imagem, de modo que a leitura não é a principal forma de interação. Utilizam também a limpeza visual, enfatizando-se os elementos principais da interface. O feedback acontece de forma imediata, utilizando sons e efeitos de comemoração quando se atinge o objetivo do jogo, ajudando o usuário a visualizar os resultados de suas ações. São interativos quando em espera, favorecendo a 
aleatoriedade e a brincadeira com os elementos da interface. Por fim, verificou-se que no aplicativo "Agnitus" é fornecido relatório de progresso das crianças aos pais.

\section{4. RECOMENDAÇÕES PARA DESENVOLVIMENTO DE INTERFACES VOLTADAS PARA A ESTIMULAÇÃO DAS INTELIGÊNCIAS MÚLTIPLAS}

Com base nos itens abordados anteriormente, foi feita lista de recomendações para o desenvolvimento de aplicativo para crianças de 3 a 5 anos que tenha como foco o estímulo das inteligências múltiplas. Além destes tópicos, foi estudado iOS Human Interface Guidelines, guia de princípios e diretrizes da Apple que orientam os designers e programadores na criação de interfaces centradas nos usuários e melhores práticas de interação. Assim, as recomendações foram agrupadas segundo os critérios abordados nos capítulos anteriores, a saber:

\subsection{Aspectos cognitivos do estágio pré-operatório}

Neste grupo foram pontuadas as características do usuário que servirão como parâmetros para o fornecimento de atividades condizentes com seu desenvolvimento cognitivo, enfatizando-se aquelas que são interessantes e aplicáveis a aplicativos mobile.

Quadro 1 - Requisitos e parâmetros relativos ao desenvolvimento cognitivo de crianças de 3 a 5 anos de idade

\begin{tabular}{|l|l|}
\hline REQUISITO & PARÂMETROS \\
\hline $\begin{array}{l}\text { Desenvolvimento } \\
\text { Cognitivo - } \\
\text { Crianças de } \mathbf{3} \text { a } 5 \\
\text { anos de idade }\end{array}$ & $\begin{array}{l}\text { Utilização dos sistemas simbólicos básicos: linguagem, números, música e } \\
\text { descrição bidimensional. (Gardner, 1995) }\end{array}$ \\
\cline { 2 - 3 } & $\begin{array}{l}\text { Relacionar significantes (palavras, fotos, desenhos, cores, etc) com seus } \\
\text { significados. (Antunes, 1998) }\end{array}$ \\
\cline { 2 - 3 } & $\begin{array}{l}\text { Estimular a utilização da coordenação motora fina (Bock, Furtado e Teixeira, } \\
\text { 1991), através dos padrões de gestos para interação com a interface - tocar, } \\
\text { arrastar, deslizar, duplo toque, beliscar (pinch), balançar (shake)* }\end{array}$ \\
\cline { 2 - 3 } & $\begin{array}{l}\text { Não se deve forçar a realização de classificação, agrupamento, ordenação ou } \\
\text { seriação. (Barros, 2000 com base nos estudos de Piaget) }\end{array}$ \\
\cline { 2 - 3 } & $\begin{array}{l}\text { Utilização do animismo, ou seja, sempre que possível, atribuir vida aos objetos. } \\
\text { (Barros, 2000 com base nos estudos de Piaget) }\end{array}$ \\
\cline { 2 - 2 } & $\begin{array}{l}\text { Deve ser intuitivo, combinando texto e imagem, de modo que a leitura não seja } \\
\text { a forma principal de interação. (Conforme análise de similares realizada) }\end{array}$ \\
\hline
\end{tabular}

Fonte: Elaborado pelo autor, com base na pesquisa realizada

\subsection{Linguagem visual para o público infantil}

Sabendo-se da importância da linguagem visual para este público, sobretudo por ainda não terem o domínio da leitura, foram pontuados neste grupo de recomendações os parâmetros para utilizar estes recursos de forma eficaz a fim de estruturar a informação visualmente, facilitar a retenção da informação e estimular a criação de mapas conceituais visuais. Os critérios citados abaixo dizem respeito ao estilo visual da interface, do acabamento formal dos elementos e das cores que serão utilizadas. 
Quadro 2 - Requisitos e parâmetros relativos à linguagem visual

\begin{tabular}{|c|c|}
\hline REQUISITO & PARÂMETROS \\
\hline \multirow[t]{6}{*}{$\begin{array}{l}\text { Linguagem } \\
\text { Visual }\end{array}$} & $\begin{array}{l}\text { Deve utilizar a limpeza visual, com plano de fundo neutro, enfatizando-se os elementos } \\
\text { principais da interface. (Conforme análise de similares realizada) }\end{array}$ \\
\hline & $\begin{array}{l}\text { Deve prezar pela simplicidade e simbolismo, ou seja, reduzindo-se o detalhe visual ao } \\
\text { mínimo possível. (Dondis, 1997) }\end{array}$ \\
\hline & $\begin{array}{l}\text { Adotar o flat design como estilo visual da interface. (Conforme análise de similares } \\
\text { realizada) }\end{array}$ \\
\hline & Definir paleta de cores puras e vibrantes (Dondis, 1997), sem demarcação de gênero. \\
\hline & Utilizar formas orgânicas/arredondadas. (Conforme análise de similares realizada) \\
\hline & $\begin{array}{l}\text { Deve utilizar a limpeza visual, com plano de fundo neutro, enfatizando-se os elementos } \\
\text { principais da interface. (Conforme análise de similares realizada) }\end{array}$ \\
\hline
\end{tabular}

Fonte: Elaborado pelo autor, com base na pesquisa realizada

\subsection{Design de Informação}

Para complementar os conceitos oferecidos pela Linguagem Visual para organizar a informação dentro da interface e deixá-la visualmente agradável ao público, faz-se imprescindível a adoção dos conceitos do Design de Informação. Tendo como base estas duas áreas de conhecimento, a informação será significativa aos usuários e as experiências serão agradáveis. Dessa forma, foram pontuadas neste grupo as recomendações para a estruturação e apresentação eficaz das informações.

Quadro 3 - Requisitos e parâmetros relativos ao Design de Informação

\begin{tabular}{|c|c|}
\hline REQUISITO & PARÂMETROS \\
\hline \multirow[t]{6}{*}{$\begin{array}{l}\text { Design de } \\
\text { Informação }\end{array}$} & $\begin{array}{l}\text { Valer-se de estratégias e atributos visuais, como cores, contrastes, tamanho e } \\
\text { textura, para que a informação seja visualizada facilmente. (Lapolli, Vanzin e Ulbricht, } \\
\text { 2014) }\end{array}$ \\
\hline & $\begin{array}{l}\text { As representações gráficas devem mostrar a evolução do sistema de forma mais } \\
\text { direta possível, associando gráficos, tipografia, movimento, som e interatividade. } \\
\text { (lida, 2005) }\end{array}$ \\
\hline & $\begin{array}{l}\text { Utilizar as metáforas visuais, com imagens e conceitos que remetem a elementos do } \\
\text { mundo real. (Lapolli, Vanzin e Ulbricht, 2014) }\end{array}$ \\
\hline & $\begin{array}{l}\text { A navegação deve ser diferenciada e envolvente, orientada a experiência e ao } \\
\text { conteúdo. (Apple Inc, 2014a) }\end{array}$ \\
\hline & $\begin{array}{l}\text { Quanto à instrução e tutoriais, fornecer ao usuário a informação que ele precisa para } \\
\text { iniciar a tarefa, utilizando animação e interatividade para facilitar o aprendizado. } \\
\text { Facilitar que o usuário recuse ou pule os tutoriais. (Apple Inc, 2014a) }\end{array}$ \\
\hline & $\begin{array}{l}\text { Valer-se de estratégias e atributos visuais, como cores, contrastes, tamanho e } \\
\text { textura, para que a informação seja visualizada facilmente. (Lapolli, Vanzin e Ulbricht, } \\
\text { 2014) }\end{array}$ \\
\hline
\end{tabular}

Fonte: Elaborado pelo autor, com base na pesquisa realizada

\subsection{Jogos na educação infantil}

Neste grupo são elencadas recomendações para que o aplicativo desperte o interesse das crianças, sendo divertido ao mesmo tempo em que é educativo, no que tange a estimulação das inteligências múltiplas. Foi somado ao tópico que abordou os conceitos de inteligências múltiplas e sua estimulação na educação infantil as conclusões feitas pela análise de similares, que destacou os pontos positivos e as lacunas de aplicativos para a faixa etária em questão. 
Quadro 4 - Requisitos e parâmetros relativos aos jogos na educação infantil

\begin{tabular}{|c|c|}
\hline REQUISITO & PARÂMETROS \\
\hline \multirow{6}{*}{$\begin{array}{l}\text { Jogos na } \\
\text { educação } \\
\text { infantil }\end{array}$} & $\begin{array}{l}\text { Oferecer desafios intrigantes e estimulantes, mas possíveis de serem concretizados } \\
\text { pelos usuários. (Antunes, 1998) }\end{array}$ \\
\hline & $\begin{array}{l}\text { Aumentar a dificuldade de acordo com o avanço dos níveis (conforme análise de } \\
\text { similares realizada) e oferecer dicas quando se nota dificuldade (inatividade) do } \\
\text { usuário. (Antunes, 1998) }\end{array}$ \\
\hline & $\begin{array}{l}\text { Estimular a busca dos próprios caminhos, possibilitando a escolha e liberdade. } \\
\text { (Antunes, 1998) }\end{array}$ \\
\hline & Deve ter começo, meio e fim. (Antunes, 1998) \\
\hline & $\begin{array}{l}\text { Proporcionar a compreensão de relações entre elementos significantes (palavras, } \\
\text { fotos, desenhos, cores, etc.) e seus significados (objetos). (Antunes, 1998) }\end{array}$ \\
\hline & $\begin{array}{l}\text { Deve ser gratificante instantaneamente (Nielsen, 2010), oferecendo premiações a } \\
\text { cada novo desafio vencido. (Conforme análise de similares realizada) }\end{array}$ \\
\hline
\end{tabular}

Fonte: Elaborado pelo autor, com base na pesquisa realizada

\subsection{Usabilidade em interfaces para crianças}

Para finalizar a lista de recomendações, os critérios de usabilidade devem ser usados em paralelo com os demais, para que a interface seja fácil de entender e simples de usar, ou seja, que a criança entenda sem necessidade de explicações sobre o que é e como se usa, além de comunicar efetivamente o que se pretende. Em síntese, a interface deve estar centrada no usuário, ou seja, as crianças de 3 a 5 anos de idade e proporcionar sua satisfação.

Quadro 5 - Requisitos e parâmetros relativos à Usabilidade

\begin{tabular}{|c|c|c|}
\hline \multirow{2}{*}{\begin{tabular}{l}
\multicolumn{1}{c}{ REQUISITO } \\
Usabilidade em \\
interfaces para \\
crianças
\end{tabular}} & \multicolumn{2}{|r|}{ PARÂMETROS } \\
\hline & \multirow[t]{5}{*}{ Feedback } & $\begin{array}{l}\text { Deve dar visibilidade ao status do sistema, informando o que } \\
\text { está acontecendo, fornecendo resposta apropriada dentro } \\
\text { de um prazo razoável. (Nielsen, 2001) }\end{array}$ \\
\hline & & $\begin{array}{l}\text { Deve-se utilizar o reconhecimento ao invés de memorização, } \\
\text { tornando objetos, ações e opções visíveis. (Nielsen, 2001) }\end{array}$ \\
\hline & & $\begin{array}{l}\text { O feedback deve ser imediato, utilizando sons e } \\
\text { comemoração quando se atinge o objetivo do jogo } \\
\text { (conforme análise de similares realizada), ajudando os } \\
\text { usuários a visualizar os resultados de suas ações. (Apple Inc, } \\
\text { 2014a) }\end{array}$ \\
\hline & & $\begin{array}{l}\text { Utilizar animação para comunicar o status e fornecer } \\
\text { feedback. (Apple Inc, 2014a) }\end{array}$ \\
\hline & & $\begin{array}{l}\text { O som pode dar aos usuários um feedback útil, mas não deve } \\
\text { ser o único mecanismo de retroalimentação. (Apple Inc, } \\
\text { 2014a) }\end{array}$ \\
\hline & Consistência & $\begin{array}{l}\text { O aplicativo deve ser consistente, uma vez que as crianças } \\
\text { repetem os caminhos aprendidos (Nielsen, 2010). Deve-se } \\
\text { utilizar a mesma terminologia e estilo; os mesmos ícones } \\
\text { devem significar as mesmas coisas. (Apple Inc, 2014a) }\end{array}$ \\
\hline & $\begin{array}{l}\text { Controle do } \\
\text { usuário e } \\
\text { liberdade }\end{array}$ & $\begin{array}{l}\text { As crianças preferem controlar inteiramente a navegação e } \\
\text { raramente utilizam a rolagem de tela (Nielsen, 2010). }\end{array}$ \\
\hline & Compatibilidade & Usar um tom informal e amigável (Apple Inc, 2014a), com \\
\hline
\end{tabular}




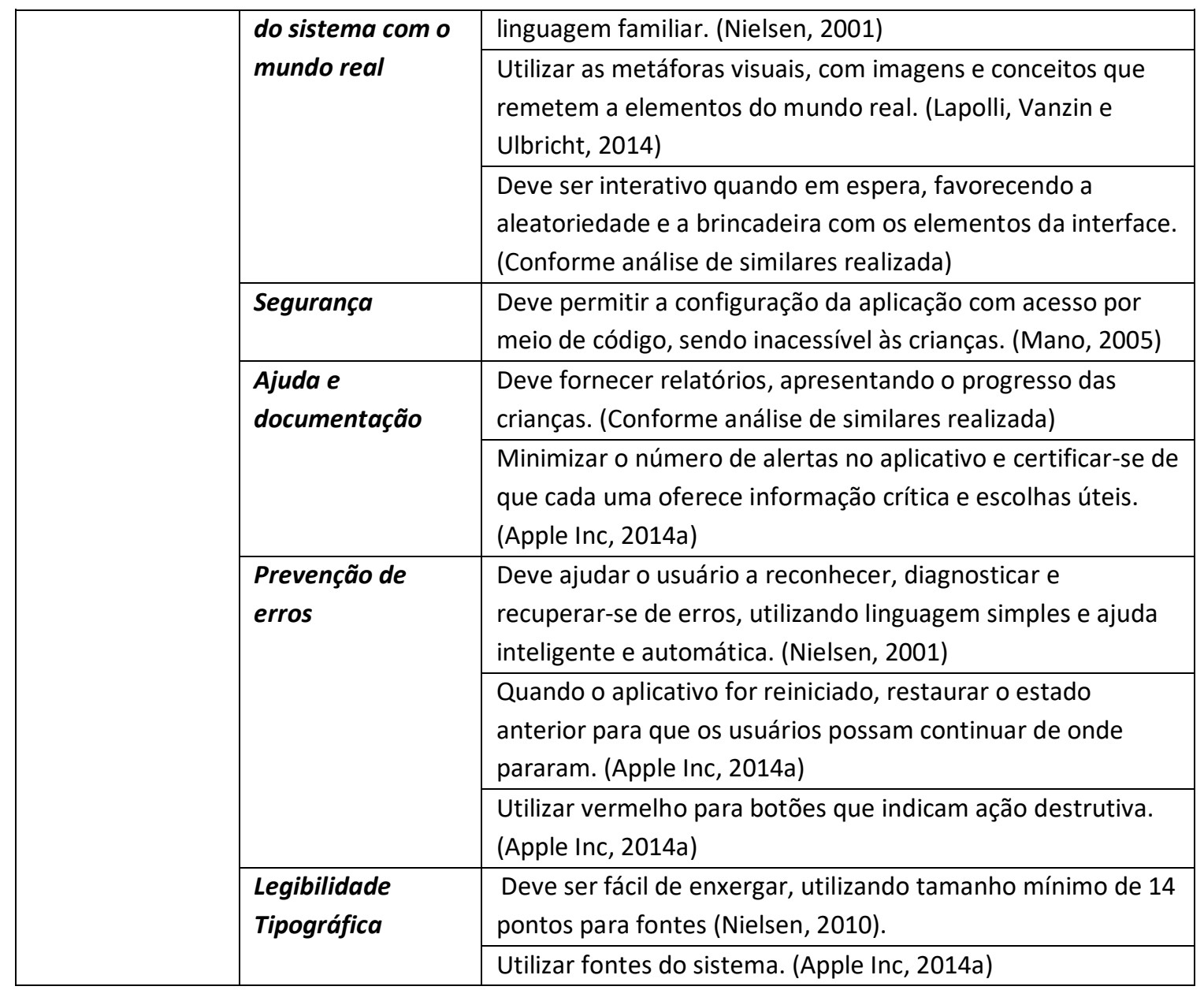

Fonte: Elaborado pelo autor, com base na pesquisa realizada

\section{CONSIDERAÇÕES FINAIS}

A partir do estudo, foi possível constatar que são vastas as possibilidades de utilizar as características cognitivas das crianças de 3 a 5 anos para oferecer jogos e atividades educacionais, sem perder o caráter lúdico e divertido. Por meio do conhecimento das características cognitivas deste público e a contribuição dos jogos na educação infantil e no desenvolvimento das inteligências múltiplas, alcançou-se o objetivo proposto no trabalho, ou seja, a elaboração da lista de recomendações para desenvolvimento de interface que auxilie a estimulação das inteligências múltiplas em crianças de 3 a 5 anos.

O método híbrido empregado atendeu ao esperado, oferecendo as bases para a realização dos procedimentos da pesquisa. A utilização da metodologia cíclica proposta por Bomfim (1995) foi satisfatória, visto que é um método flexível, permitindo o retorno entre as etapas, sempre que preciso. Este retorno foi realizado quando havia a necessidade de estudar novas bases teóricas e novos conceitos, que seriam imprescindíveis para enriquecer a lista de recomendações. Quanto à metodologia proposta por Inhamuns (2011), foi necessária sua adaptação, visto que o autor primeiramente identifica o problema, depois analisa interfaces similares e, por fim, parte para a fundamentação teórica, direcionada às fragilidades das aplicações analisadas. No presente estudo, porém, o referencial teórico ofereceu as bases para a análise de sistemas similares, sendo possível ter mais clareza na identificação das suas fragilidades e potencialidades. 
Quanto aos autores estudados, conclui-se que ofereceram um forte embasamento teórico para fundamentar as escolhas das recomendações e alcançar o resultado do projeto. Porém, embora Piaget tenha um vasto estudo sobre os aspectos cognitivos das crianças, sua abordagem é focada, em sua maioria, naquilo que este público não consegue fazer, como a seriação, classificação e inclusão de classe. Em novas pesquisas, propõe-se a utilização de autores que estudam a nova geração de crianças e seus principais aspectos como nativos digitais.

Posteriormente, a partir do referencial teórico e análise de similares, obtiveram-se as recomendações como segundo produto do trabalho, que, embora possuam uma abordagem voltada à estimulação das inteligências múltiplas, por usar jogos propostos por Antunes (1998), podem também ser utilizadas para aplicações educacionais de um modo geral, com temas diversos, voltados para este público-alvo.

O projeto, porém, não contou com os testes de usabilidade, que pudessem verificar junto ao público se é efetivamente usável e inteligível. Outra lacuna verificada no projeto é a ausência de jogos que estimulem as inteligências inter e intrapessoal, musical e linguística, pois, neste momento, a quantidade de jogos limitou-se a oito.

Dessa forma, como projetos futuros, busca-se a implementação das recomendações em uma interface e posterior aplicação de testes de usabilidade. Além disso, busca-se expandir a quantidade de jogos, que contemplem as inteligências não abordadas, ambientados em diversos cenários familiares a este público, como circo, praia, fundo do mar, etc.

Portanto, ressalta-se que a interligação do Design com outras áreas do conhecimento como a Educação, proporciona o crescimento profissional e social, com o desenvolvimento de produtos funcionais, usáveis e que contribuam efetivamente para o desenvolvimento da aprendizagem das crianças. É uma área com grande potencial de estudos, sendo possível aplicar o design como diferencial de qualidade e facilidade de uso, a multimídia para combinar os recursos visuais e auditivos de forma compreensível e enriquecedora, e a comunicação para contribuir efetivamente para o processo informacional da aprendizagem e desenvolvimento das inteligências múltiplas das crianças na idade pré-escolar.

\title{
REFERÊNCIAS
}

\section{AGNITUS, INC. Aplicativo Agnitus Kids Learning Program. 2014.}

ANTUNES, Celso. Jogos para a estimulação das múltiplas inteligências. Petrópolis, RJ: Vozes, 1998.

APPLE INC. iOS Human Interface Guidelines, Apple, 2014. Disponível em: < https://developer.apple.com/library/ios/documentation/UserExperience/Conceptual/ MobileHIG/>. Acesso em: 19 abril 2014a

\author{
APPLE INC. ITunes - PlayKids - Vídeos e jogos educativos infantis para aprender \\ brincando e atividades para crianças e bebês. Disponível em: \\ $<$ https://itunes.apple.com/br/app/playkids-videos-e-jogos- \\ educativos/id613398383 ?mt=8>. Acesso em: 06 agosto 2014b
}


APPLE INC. ITunes - Talking Pocoyo Grátis HD. Disponível em: < https://itunes.apple.com/br/app/talking-pocoyo-gratis-hd/id547563774?mt=8>. Acesso em: 06 agosto $2014 \mathrm{c}$

APPLE INC. ITunes - Agnitus Kids Learning Program. Disponível em: < https://itunes.apple.com/br/app/agnitus-kids-learning-program/id867480619?mt=12 >. Acesso em: 06 agosto 2014d

BARROS, Célia Silva Guimarães. Pontos de Psicologia do Desenvolvimento. São Paulo: Ática, 2000.

BOCK, Ana Maria; FURTADO, Odair; TEIXEIRA, Maria de Lourdes. Psicologias: uma introdução ao estudo de psicologia. São Paulo: Saraiva,1991.

BOMFIM, Gustavo Amarante. Metodologia para desenvolvimento de projetos. João Pessoa: Editora Universitária, 1995.

DONDIS, Donis A. Sintaxe da linguagem visual. Tradução Jefferson Luiz Camargo. 2. ed. São Paulo: Martins Fontes, 1997.

FARIAS, Bruno Serviliano; TEIXEIRA, Mário Meireles. Análise de elementos visuais em jogos digitais: a função da navegação, instrução e comunicação em dispositivos portáteis. Revista Brasileira de Design da Informação, São Paulo, v. 10, p. 245-261, 2013. Disponível em:

<http://www.infodesign.org.br/infodesign/article/view/200/159>. Acesso em: 06 maio 2015.

FILHO, João Gomes. Gestalt do Objeto: sistema de leitura visual da forma. 2. ed. São Paulo: Escrituras, 2000, 127 p.

GARDNER, Howard. Inteligências múltiplas. A teoria na pratica. Porto Alegre: Artes Médicas, 1995.

IIDA, Itiro. Ergonomia: projeto e produção. 2. ed. São Paulo: Edgard Blücher, 2005. 632 p.

INHAMUNS, Antonio Felipe Cumaru. Recomendações ao desenvolvimento de uma interface multimídia voltada para a educação ambiental. 2011. 91 p. Monografia (Especialização) - Pós-graduação em Design, Comunicação e Multimídia, Instituto de Ensino Superior Fucapi, Manaus, 2011.

KRUG, Steve. Não me faça pensar: uma abordagem de bom senso à usabilidade na web. 2. ed. Rio de Janeiro: Alta Books, 2010.

KULPA, Cínthia Costa. A contribuição de um modelo de cores na usabilidade das interfaces computacionais para usuários de baixa visão. 2009. 191 p. Dissertação (Mestrado em Design) - Programa de Pós-Graduação em Design, Universidade Federal do Rio Grande do Sul, Porto Alegre, 2009.

LAPOLLI, Mariana; VANZIN, Tarcísio; ULBRICHT, Vania R. Organização da informação em narrativas infográficas na web voltadas para o processo de ensino-aprendizagem. Revista Brasileira de Design da Informação, São Paulo, v. 11, p. 36-49, 2014. Disponível em: < http://www.infodesign.org.br/infodesign/article/view/247>. Acesso em: 10 jun. 2015. 
MANO, Alexandre Sérgio. Interfaces de computador para crianças - avaliação e construção. 2005. 130 p. Tese (Mestrado em Informática) - Escola de Engenharia, Universidade do Minho, Minho, 2005.

MANO, Alexandre; CAMPOS, José C. Usabilidade em interfaces para crianças. Jornal de Ciências Cognitivas, Sociedade Portuguesa de Ciências Cognitivas, 2006. Disponível em: <http://jcienciascognitivas.home.sapo.pt/> Acesso em: 20 jun. 2014.

MOVILE INTERNET MOVEL S.A. Aplicativo PlayKids - Vídeos e jogos educativos infantis para aprender brincando e atividades para crianças e bebês. 2014.

MUNARI, Bruno. Das coisas nascem coisas. Tradução José Manuel de Vasconcelos. 2. ed. São Paulo: Martins Fontes, 2008.

NIELSEN, Jakob. Websites das crianças: problemas de usabilidade em Design para Crianças, Nielsen Norman Group, 2010. Disponível em: < https://www.nngroup.com/articles/childrens-websites-usability-issues/>. Acesso em: 29 jun. 2014.

; LORANGER, Hoa. Usabilidade na Web: projetando websites com qualidade. Tradução Edson Furmankiewicz \& Carlos Schafranski, Docware Traduções Técnicas. 5a reimpressão. Rio de Janeiro: Elsevier, 2007.

PORTUGAL, Cristina. Questões complexas do design da informação e de interação. Revista Brasileira de Design da Informação, São Paulo, v. 7, p. 1-6, 2010. Disponível em < http://www.infodesign.org.br/infodesign/article/view/89>. Acesso em: 09 maio 2015.

PREECE, Jennifer; ROGER, Yvone; SHARP, Helen. Design de interação: além da interação homem-computador. Trad. Viviane Possamai. Porto Alegre: Bookman, 2005.

TEIXEIRA, Narle Silva. A linguagem visual do livro didático. 2008. 213 p. Dissertação (Mestrado em Educação) - Programa de Pós-Graduação em Educação, Universidade Federal do Amazonas, Manaus, 2008.

ZINKIA ENTERTAINMENT, S.A. Aplicativo Talking Pocoyo Grátis HD. 2014. 